\title{
Comparative study of proteasome inhibitory, synergistic antibacterial, synergistic anticandidal, and antioxidant activities of gold nanoparticles biosynthesized using fruit waste materials
}

\author{
This article was published in the following Dove Press journal: \\ International Journal of Nanomedicine \\ 14 September 2016 \\ Number of times this article has been viewed
}

\section{Jayanta Kumar Patra' \\ Kwang-Hyun Baek ${ }^{2}$}

'Research Institute of Biotechnology and Medical Converged Science, Dongguk University-Seoul, Ilsandong-gu, Gyeonggi-do, ${ }^{2}$ Department of Biotechnology, Yeungnam University, Gyeongsan, Gyeongbuk, South Korea
Correspondence: Kwang-Hyun Baek Department of Biotechnology, Yeungnam University, 280 Daehak-ro, Gyeongsan,

Gyeongbuk 3854I, South Korea

Tel +82538103029

Fax +82538104769

Email khbaek@ynu.ac.kr

\begin{abstract}
The aim of this study was to compare the biological synthesis of gold nanoparticles (AuNPs) generated using the aqueous extracts of outer oriental melon peel (OMP) and peach. The synthesized OMP-AuNPs and peach extract (PE)-AuNPs were characterized by ultravioletvisible spectroscopy, field emission scanning electron microscopy, energy dispersive X-ray analysis, X-ray powder diffraction, Fourier transform infrared spectroscopy, and thermogravimetric analysis. The surface plasmon resonance spectra were obtained at $545 \mathrm{~nm}$ and $540 \mathrm{~nm}$ for OMP-AuNPs and PE-AuNPs, respectively. The estimated absolute crystallite size of the synthesized AuNPs was calculated to be $78.11 \mathrm{~nm}$ for OMP-AuNPs and $39.90 \mathrm{~nm}$ for PE-AuNPs based on the Scherer equation of the X-ray powder diffraction peaks. Fourier transform infrared spectroscopy results revealed the involvement of bioactive compounds present in OMP and peach extracts in the synthesis and stabilization of synthesized AuNPs. Both the OMP-AuNPs and PE-AuNPs showed a strong antibacterial synergistic activity when combined with kanamycin (9.38-20.45 mm inhibition zones) and rifampicin (9.52-25.23 $\mathrm{mm}$ inhibition zones), and they also exerted a strong synergistic anticandidal activity (10.09-15.47 $\mathrm{mm}$ inhibition zones) when combined with amphotericin B against five pathogenic Candida species. Both the OMP-AuNPs and PE-AuNPs exhibited a strong antioxidant potential in terms of 1,1-diphenyl-2-picrylhydraxyl radical scavenging, nitric oxide scavenging, 2,2'-azino-bis(3-ethylbenzothiazoline-6-sulphonic acid) radical scavenging, and a reducing power, along with a strong proteasome inhibitory potential that could be useful in cancer drug delivery and cancer treatments. The PE-AuNPs showed comparatively higher activity than OMP-AuNPs, which could be attributed to the presence of rich bioactive compounds in the PE that acted as reducing and capping agents in the synthesis of PE-AuNPs. Overall, the results of the current investigation highlighted a novel green technology for the synthesis of AuNPs using food waste materials and their potential applications in the biomedical, pharmaceutical, and cosmetic industries.
\end{abstract}

Keywords: antibacterial, anticandidal, antioxidant, Cucumis melo, gold nanoparticles, proteasome inhibitor, Prunus persica

\section{Introduction}

Nanotechnology is a field of applied science and technology that deals with materials in the nanoscale range with large surface areas. ${ }^{1}$ These nanoscale particles, which are most commonly known as nanoparticles (NPs), have the ability to build micro-/macro-materials and products with atomic precision. NPs have recently drawn tremendous attention because of their potential applications in chemical, catalytic, electronic, optical, 
mechanical, magnetic, and medical fields. ${ }^{2-4}$ NPs are usually synthesized by chemical or physical approaches because of their inherent advantage in producing well-defined NPs with fairly controllable shapes and sizes. ${ }^{5}$ However, these methods involve tedious treatments, such as microemulsion, laser photolysis, hydrothermal induction, and toxic chemical reduction, along with expensive physical techniques and equipment, and are potentially toxic to the environment. ${ }^{6-8}$ Thus, to avoid the adverse effects of NPs on the environment, the concept of green chemistry evolved. This method utilizes biological organisms for the fabrication of NPs.

In general, the synthesis of NPs using biological organisms such as microorganisms, plants or plant extracts, algae, and fungi is environmentally benign and cost-effective. ${ }^{9}$ However, there are certain drawbacks in the synthesis of NPs using microorganisms because of difficulties in separation and purification procedures. ${ }^{10}$ In contrast, plant biomass-mediated biosynthesis of NPs has recently attracted a great deal of attention because of their easy synthesis and extraction processes. ${ }^{11}$ Naturally available biological, food, and agricultural waste materials have not been extensively investigated for the synthesis of different types of NPs.

Oriental melons and peaches are commonly consumed in East Asia. Basically, the juicy internal portions of both fruits are edible, while the outer peels are generally discarded and considered useless. The oriental melon (Cucumis melo $\mathrm{L}$. var. makuwa) that belongs to the family Cucurbitaceae is primarily grown in South Korea, People's Republic of China, and Japan. ${ }^{12}$ The word melon is derived from the Latin name "melopepo" meaning melon. The fruit is $\sim 10 \mathrm{~cm}$ long and typically weighs slightly more than one pound $(0.45 \mathrm{~kg}){ }^{12}$ This fruit has been utilized in Korean folk medicine for treatment of acute gastritis, fever, mental disorders, dysuria, jaundice, alcoholism, and hyperesthesia/paralysis. ${ }^{13,14}$ Peach (Prunus persica $\mathrm{L}$. Batsch) that belongs to the family Rosaceae is a fruit of the deciduous tree native to Northwest China, between the Tarim basin and the northern slopes of the Kunlun Shan mountains. ${ }^{15}$ This fruit is cultivated in many countries including the People's Republic of China, Japan, South Korea, and Vietnam. Peaches are considered as important economic crops with potential bioactive compounds and medicinal benefits. ${ }^{16,17}$ The fruit is rich in a number of phenolic compounds, including chlorogenic acid, catechin, epicatechin, rutin, and cyanidin-3-glucoside,${ }^{18}$ and is utilized as a demulcent, antiscorbutic, and a stomachic agent. ${ }^{19}$

NPs, especially gold, have recently attracted a great deal of attention due to their nontoxic nature and extensive applications in biomedical, chemistry, and electronics fields. ${ }^{20,21}$ Gold NPs (AuNPs) can be easily synthesized and exhibit intense surface plasmon resonance (SPR) with high chemical and thermal stability. ${ }^{21}$ Investigation of the morphological behavior of gold nanostructures is important because of their wide usage in catalysis, optics, optical electronics, microelectronics, biodiagnostics, imaging, and biological and chemical sensing techniques. ${ }^{21,22}$ Biomedical applications of AuNPs such as drug and gene delivery, protein and pathogen detection, deoxyribonucleic acid labeling, fluorescent labeling, tissue engineering, photothermal ablation, and as contrast agents for magnetic resonance imaging and other imaging methods have become a highly active area of research during recent years. ${ }^{23,24}$

Many studies have investigated the biosynthesis of AuNPs using various plant extracts. ${ }^{25-28}$ However, only a few studies have investigated the synthesis of AuNPs using food waste materials..$^{29,30}$ In the current study, the reducing ability of aqueous extracts of the outer peels of two common fruits, oriental melon and peach, were investigated to determine their usefulness for the synthesis of AuNPs. In addition, their antibacterial, anticandidal, antioxidant, and proteasome inhibitory potentials were evaluated.

\section{Materials and methods}

\section{Preparation of aqueous extract of fruit waste materials}

The fruits of oriental melon (Cucumis melo L. var. makuwa; Figure 1A) and peach (Prunus persica L.; Figure 1B) were purchased from a local market (Gyeongsan, South Korea). The fruits were washed thoroughly with double-distilled water and dried with tissue paper, and the outer nonedible portion of the fruits was peeled off using a peeler. The outer peels were subsequently cut into small pieces $(\sim 10 \mathrm{~mm})$ with a knife, divided into $50 \mathrm{~g}$ aliquots, and immersed in $250 \mathrm{~mL}$ of deionized water in two separate $500 \mathrm{~mL}$ conical flasks.
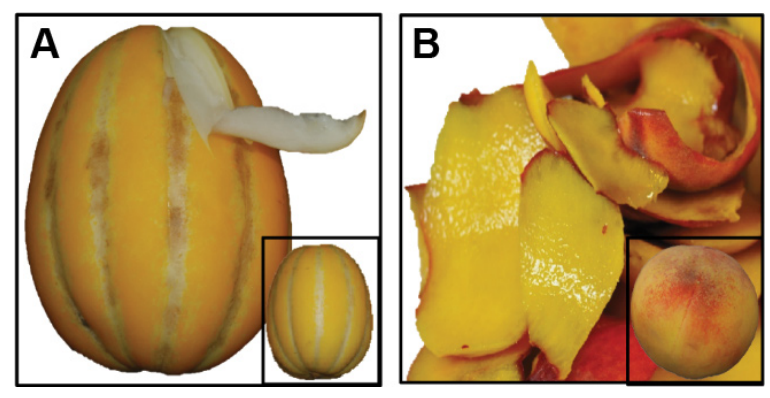

Figure I Fruit peels of oriental melon (Cucumis melo) (A) and peach (Prunus persica) (B) used for the synthesis of AuNPs.

Abbreviation: AuNPs, gold nanoparticles. 
The mixtures were subsequently boiled for 15 minutes with continuous stirring using a magnetic stirrer, after which the aqueous oriental melon peel (OMP) extract and the aqueous peach extract $(\mathrm{PE})$ were cooled to room temperature. Both the OMP and peach extracts were then filtered through Whatman No 1 filter paper, collected into separate sterilized bottles, and kept at $4^{\circ} \mathrm{C}$ until further use.

\section{Biosynthesis of AuNPs using OMP and peach extracts}

Auric chloride $\left(\mathrm{AuCl}_{3}\right.$; Sigma-Aldrich Co., St Louis, $\mathrm{MO}$, USA) was used as the precursor element for the synthesis of AuNPs. Prior to the synthesis, $1 \mathrm{mM} \mathrm{AuCl}_{3}$ solution was prepared in double-distilled water in an amber bottle. Approximately $100 \mathrm{~mL}$ of $\mathrm{AuCl}_{3}$ solution was then placed into two separate $500 \mathrm{~mL}$ conical flasks, after which $10 \mathrm{~mL}$ of OMP extract was added to one flask and $10 \mathrm{~mL}$ of PE to another flask dropwise using a separating funnel. Samples were then incubated at room temperature with continuous stirring for 24 hours. ${ }^{31}$ The bioreduction and color change of $\mathrm{AuCl}_{3}$ to AuNPs was then monitored with respect to the incubation time. After 24 hours, the synthesized AuNP solution (OMP-AuNPs and PE-AuNPs) was centrifuged at $12,000 \mathrm{rpm}$ for 30 minutes in a high-speed centrifuge machine (Supra 22K; Hanil Science Industrial Co., Ltd., Daejeon, South Korea). The supernatant was then discarded, and the pellets were washed twice with distilled water and dried to powder using a vacuum dryer (LVS 201T; ILMVAC GmbH, Ilmenau, Germany).

\section{Characterization of the synthesized AuNPs}

The synthesized OMP-AuNPs and PE-AuNPs were characterized by ultraviolet (UV)-visible spectroscopy, field emission scanning electron microscopy (FE-SEM), energy dispersive X-ray (EDX) analysis, X-ray powder diffraction (XRD), Fourier-transform infrared (FT-IR) spectroscopy, and thermogravimetric (TG) analysis. ${ }^{31,32}$

The bioreduction of $\mathrm{Au}$ ions to AuNPs in the reaction medium by the action of OMP and peach extracts was monitored by measuring the absorption spectra of the colloidal solution between $400 \mathrm{~nm}$ and $700 \mathrm{~nm}$ using a microplate reader (Infinite 200 PRO NanoQuant; Tecan, Mannedorf, Switzerland). The surface morphology of both OMP-AuNPs and PE-AuNPs was analyzed using an FESEM. Prior to the analysis, the OMP-AuNPs and PE-AuNPs were ground into fine powder using an agate mortar and pestle and then uniformly spread on the carbon tapes attached over the sample holder. The samples were subsequently sputter coated with platinum in an ion coater for 120 seconds, after which they were observed using a FE-SEM (S-4200; Hitachi Ltd., Tokyo, Japan). The elemental composition of the OMPAuNPs and PE-AuNPs was determined using an EDX detector (energy dispersive spectroscopy; EDAX Inc., Mahwah, NJ, USA) attached to the SEM machine. The nature of the powdered OMP-AuNPs and PE-AuNPs was determined using an XRD machine (X'Pert MRD model; PANalytical, Almelo, the Netherlands). The NPs were dried at $60^{\circ} \mathrm{C}$ in a vacuum oven and ground into fine powder using an agate mortar and pestle. XRD analysis was performed at $30 \mathrm{kV}$ and $40 \mathrm{~mA}$ with $\mathrm{Cu} \mathrm{K} \alpha$ radians $(1=1.5406 \AA)$ at an angle of $2 \theta$, while scanning from $20^{\circ}$ to $90^{\circ} \cdot{ }^{31}$ FT-IR analysis of OMP, PE, powdered OMP-AuNPs, and powdered PE-AuNPs was conducted using an FT-IR spectrophotometer (Jasco 5300; Jasco, Easton, MD, USA) in the wavelength range of $400-4,000 \mathrm{~cm}^{-1}$. Prior to use, the powdered OMP-AuNPs and PE-AuNPs were blended with powdered potassium bromide $(\mathrm{KBr})$ in a 1:100 ratio, then compressed into a $2 \mathrm{~mm}$ semitransparent disk to prepare a thin film of NPs. The OMP and peach extracts were used directly for FT-IR analysis. Both the NPs and OMP and peach extracts were analyzed for various modes of vibrations for the presence of different types of functional groups. The TG/derivative TG (DTG) analysis of the powdered OMP-AuNPs and PE-AuNPs was conducted using a TG analysis machine (SDT Q600; TA Instruments, New Castle, DE, USA). Prior to use, the powdered OMPAuNPs and PE-AuNPs were placed in an alumina pan and heated from $20^{\circ} \mathrm{C}$ to $700^{\circ} \mathrm{C}$ at a ramping time of $10^{\circ} \mathrm{C} / \mathrm{min}$ under nitrogen atmosphere.

\section{Synergistic antibacterial activity of synthesized AuNPs}

The synergistic antibacterial potential of both OMP-AuNPs and PE-AuNPs was determined against five different foodborne bacteria, namely Bacillus cereus American Type Culture Collection (ATCC) 13061, Listeria monocytogenes ATCC 19115, Staphylococcus aureus ATCC 49444, Escherichia coli ATCC 43890, and Salmonella typhimurium ATCC 43174, using the standard disk diffusion method. ${ }^{33,34}$ The pathogenic bacteria were obtained from the American Type Culture Collection (ATCC, Manassas, VA, USA) and maintained in nutrient broth (Difco; Becton, Dickinson and Company, Sparks Glencoe, MD, USA) medium at $-80^{\circ} \mathrm{C}$. Immediately before use, a colloidal solution of OMP-AuNPs and PE-AuNPs was prepared by dissolving $1,000 \mu \mathrm{g} / \mathrm{mL}$ in $5 \%$ dimethyl sulphoxide (DMSO), then sonicated at $30^{\circ} \mathrm{C}$ 
for 15 minutes. Filter paper disks containing $25 \mu \mathrm{g}$ of the test compound per disk were used for the initial antibacterial activity test. OMP and peach extracts were taken as extract controls, and kanamycin and rifampicin at $5 \mu \mathrm{g} / \mathrm{disk}$ were taken as positive controls, while 5\% DMSO was used as the negative control. To explore the synergistic effects of the AuNPs, $1,000 \mu \mathrm{g} / \mathrm{mL}$ of OMP-AuNPs or PE-AuNPs were mixed in a $1: 1$ ratio with $200 \mu \mathrm{g} / \mathrm{mL}$ of the two standard antibiotics separately and then sonicated for 15 minutes at room temperature. A total of $50 \mu \mathrm{L}$ of the mixture of AuNPantibiotics containing $25 \mu \mathrm{g}$ AuNPs and $5 \mu \mathrm{g}$ antibiotics were put on the filter paper disk, dried, and used for determination of the synergistic antibacterial effect. The diameter of zones of inhibition around each paper disk was measured after 24 hours of incubation at $37^{\circ} \mathrm{C}$ to determine the synergistic antibacterial effect of the mixture of AuNPs/antibiotics.

\section{Synergistic anticandidal activity of synthesized AuNPs}

The synergistic anticandidal activity of OMP-AuNPs or PEAuNPs with a standard anticandidal agent, amphotericin B, was determined against five different pathogenic Candida species, namely Candida albicans KACC 30003 and KACC 30062, Candida glabrata KBNO6P00368, Candida geochares KACC 30061, and Candida saitoana KACC 41238, using the disk diffusion method. ${ }^{35}$ All Candida strains were obtained from the Korean Agricultural Culture Collection (KACC, Suwon, South Korea), except for C. glabrata KBNO6P00368, which was obtained from Chonbuk National University Hospital (Cheongju, South Korea). Filter paper disks containing $50 \mu \mathrm{g} /$ disk of AuNPs were initially tested for their anticandidal activity. To explore the synergistic anticandidal activity, the OMP-AuNPs or PE-AuNPs $(2,000 \mu \mathrm{g} / \mathrm{mL})$ were mixed at a $1: 1$ ratio with amphotericin $\mathrm{B}(200 \mu \mathrm{g} / \mathrm{mL})$ separately and then sonicated for 15 minutes at room temperature. Filter paper disks were prepared by adding $50 \mu \mathrm{L}$ of the AgNPs/amphotericin B mixture solution to the sterile paper disks, which finally contained $50 \mu \mathrm{g}$ AuNPs and $5 \mu \mathrm{g}$ amphotericin B/disk. Plates of potato dextrose agar (Difco) were spread uniformly with the Candida species grown in potato dextrose broth, after which the filter paper disks were placed over it and incubated at $28^{\circ} \mathrm{C}$ for 48 hours. OMP and peach extracts were taken as extract controls, amphotericin $\mathrm{B}$ at $5 \mu \mathrm{g} /$ disk were taken as positive control, while 5\% DMSO was used as the negative control. Finally, the diameters of the zones of inhibition around each paper disk were measured to determine the synergistic anticandidal activity of the mixture of AuNPs/amphotericin B.
Antioxidant activity of synthesized AuNPs The in vitro antioxidant potential of the AuNPs was determined by four antioxidant assays, including 1,1-diphenyl2-picrylhydraxyl (DPPH) free radical scavenging, nitric oxide scavenging, 2,2'-azino-bis(3-ethylbenzothiazoline6-sulphonic acid) (ABTS) free radical scavenging, and a reducing power assay. The OMP-AuNPs, PE-AuNPs, and butylated hydroxyl toluene (BHT), which was taken as the standard reference compound, were used at $20-100 \mu \mathrm{g} / \mathrm{mL}$ for all assays. The DPPH free radical scavenging potential of both OMP-AuNPs and PE-AuNPs was determined as described by Braca et al. ${ }^{36}$ The absorbance of the reaction mixtures was recorded at $517 \mathrm{~nm}$ using a microplate reader, and the results in terms of the percentage scavenging effect were calculated using the following equation:

$$
\% \text { scavenging }=\frac{\mathrm{Abs}_{\mathrm{c}}-\mathrm{Abs}_{\mathrm{t}}}{\mathrm{Abs}_{\mathrm{c}}} \times 100
$$

where $\mathrm{Abs}_{\mathrm{c}}$ is the absorbance of the control and $\mathrm{Abs}_{\mathrm{t}}$ is the absorbance of the treatment.

The nitric oxide radical scavenging potential of both OMP-AuNPs and PE-AuNPs was determined by the standard method as described by Makhija et al. ${ }^{37}$ The absorbance of the reaction mixtures was measured at $546 \mathrm{~nm}$ using a microplate reader, and the results in terms of the percentage scavenging effect were calculated according to Equation 1. The ABTS radical scavenging activities of OMP-AuNPs and PE-AuNPs were determined as described by Thaipong et al. ${ }^{38}$ The absorbance of the reaction mixtures was recorded at $750 \mathrm{~nm}$ using a microplate reader, and the results in terms of the percentage scavenging effect were calculated according to Equation 1. The reducing powers of the OMP-AuNPs and PE-AuNPs were determined using the procedure described by Patra and Baek. ${ }^{39}$ The reducing power of AuNPs was determined in terms of the absorbance value at $700 \mathrm{~nm}$.

\section{Proteasome inhibitory activity of synthesized AuNPs}

The proteasome inhibitory potentials of OMP-AuNPs and PE-AuNPs were assayed using the 20S Proteasome Assay Kit for drug discovery (ENZO Life Sciences, Farmingdale, NY, USA) according to the manufacturer's protocols. Three different concentrations of both OMP-AuNPs and PE-AuNPs (1 $\mu \mathrm{g} / \mathrm{mL}, 10 \mu \mathrm{g} / \mathrm{mL}$, and $100 \mu \mathrm{g} / \mathrm{mL})$ and epoxomicin, a standard reference compound $(0.56 \mu \mathrm{g} / \mathrm{mL}, 2.78 \mu \mathrm{g} / \mathrm{mL}$, and $5.56 \mu \mathrm{g} / \mathrm{mL}$ ) were used for the assay. Suc-LLVYAMC (37.5 mM) was used as the substrate to estimate the 
chymotrypsin-like proteasomal activity of the AuNPs in a 96-well microplate from 1 minute to 12 minutes of incubation. The fluorescence intensities were measured at an excitation wavelength of $350 \mathrm{~nm}$ and emission wavelength of $440 \mathrm{~nm}$ at a $30^{\circ} \mathrm{C}$ reaction temperature using the microplate reader.

\section{Statistical analysis}

All data were calculated as mean \pm SD. Statistical analysis using one-way ANOVA followed by Duncan's test at the $5 \%$ level of significance $(P<0.05)$ was conducted using the Statistical Analysis Software (SAS, Version: SAS 9.4; SAS Institute Inc., Cary, NC, USA).

\section{Results and discussion Synthesis and characterization of AuNPs}

There have been many reports on the use of whole fruits in various biological activities and medicinal potentials; however, only a few studies have investigated the importance of their peels. Fruit peels are rich in polyphenolic compounds, flavonoids, ascorbic acid, and a number of other biologically active components that have positive effects on health. ${ }^{40-43}$ In the recent past, there have been reports on the pharmacological effects of some fruit peel extracts against diseases such as cardiovascular problems, thyroid abnormalities, and diabetes mellitus. ${ }^{29,43,44}$ Thus, we investigated the synthesis of AuNPs utilizing the fruit peels of two fruits common in East Asia, oriental melon and peach, and then compared their potential applications. AuNPs were synthesized by taking $\mathrm{AuCl}_{3}$ as the precursor element and both OMP and peach extracts as the reducing agents (Figure 1). The bioreduction of $\mathrm{Au}^{+}$to $\mathrm{Au}^{0}$ (AuNPs) first started vigorously after 1 hour of incubation in the PE-mediated synthesis compared to the OMP-mediated AuNP synthesis, during which time there was a gradual change in the color of the reaction mixture from colorless to purple (Figure 2, inset). The solution was dark purple at 6 hours of incubation in both the cases; however, the

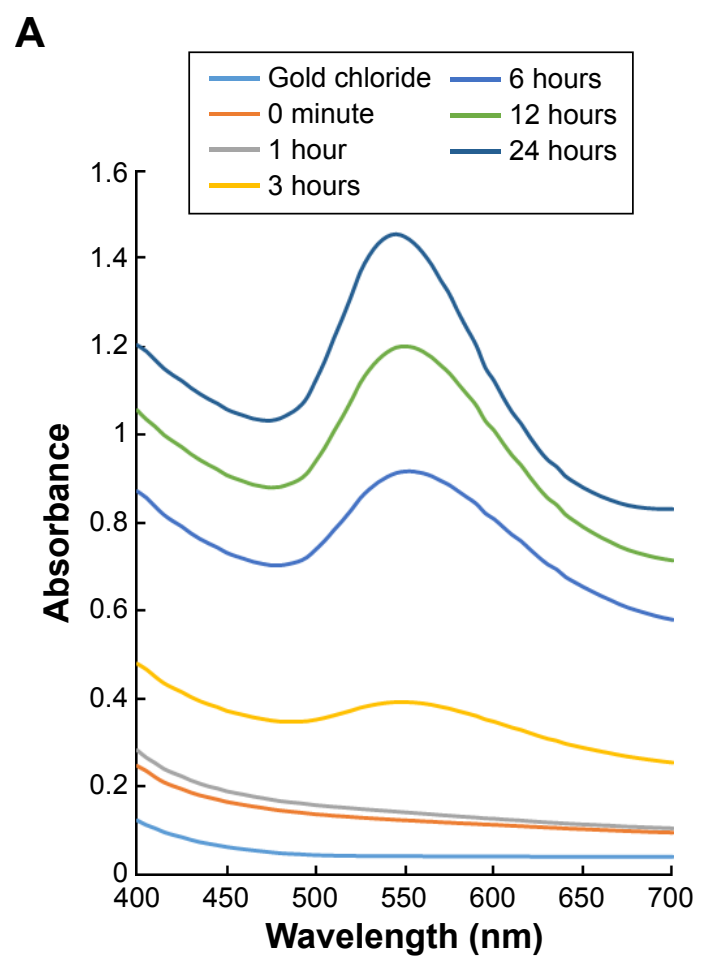

B
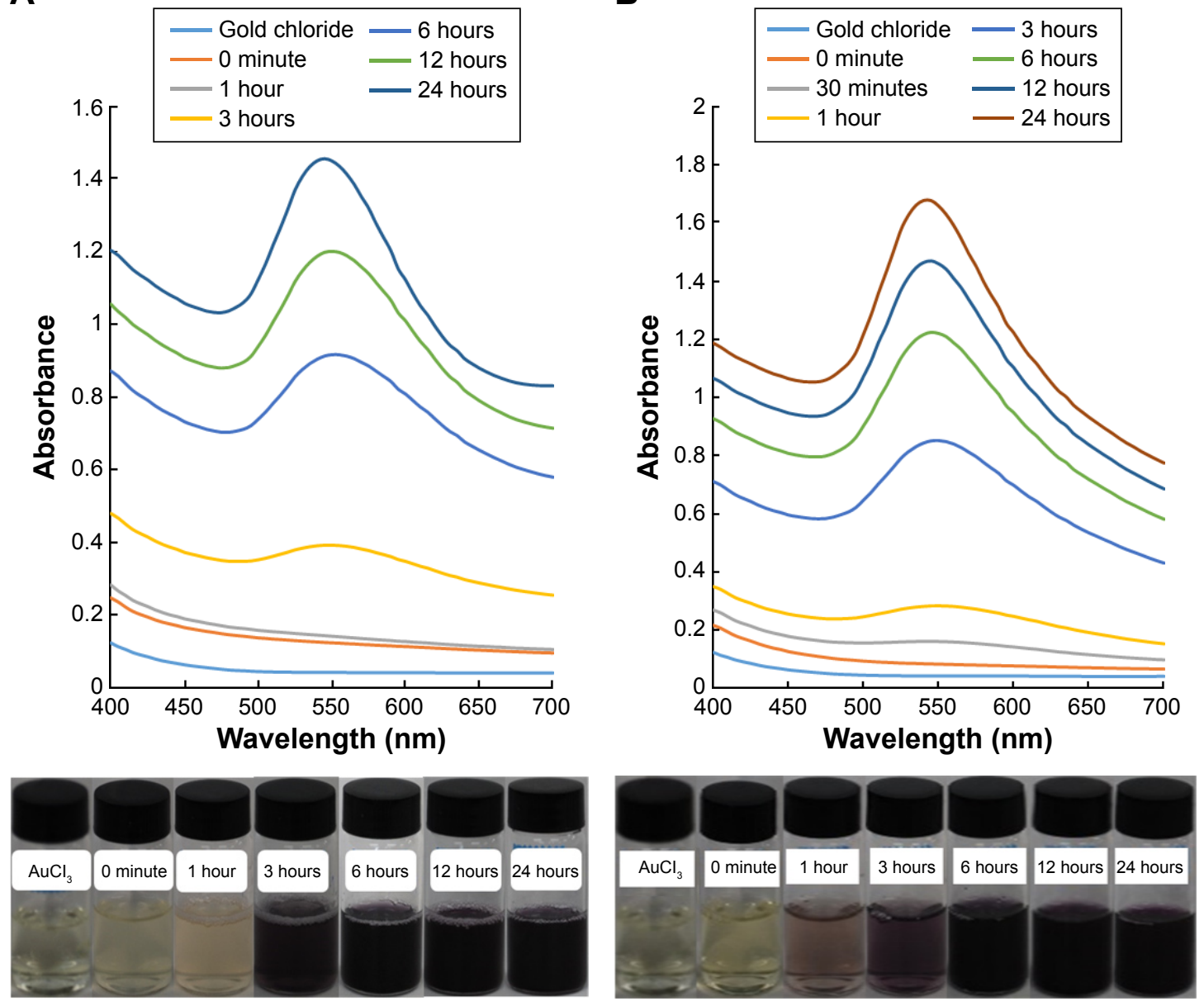

Figure 2 UV-visible spectroscopy and change in color of the reaction mixture at different time intervals of the synthesized OMP-AuNPs and PE-AuNPs. Notes: (A) OMP-AuNPs; (B) PE-AuNPs.

Abbreviations: AuNPs, gold nanoparticles; OMP, oriental melon peel; PE, peach extract; UV, ultraviolet. 
reaction continued for up to 24 hours until the complete reduction of $\mathrm{Au}^{+}$in the reaction mixture (Figure 2, inset).

The dark purple color unveiled by the metallic colloidal AuNPs was due to the articulate excitation of all of the free electrons within the conduction band that led to the in-phase oscillation referred to as the SPR. ${ }^{45}$ The bioactive compounds present in both fruit peels might have been responsible for the bioreduction of $\mathrm{Au}^{+}$to AuNPs. The oriental melon is a rich source of vitamin A, vitamin C, 5-hydroxy-6,7,8-trimethoxy2,3-dimethyl-4H-chromen-4-one, and anhalinine; ${ }^{46,47}$ therefore, it has potential for use as a reducing agent to synthesize OMP-AuNPs. Similarly, peach is rich in phenolic compounds, including chlorogenic acid, catechin, epicatechin, rutin, and cyanidin-3-glucoside; ${ }^{18}$ therefore, it might be useful as a reducing agent to synthesize PE-AuNPs. Following synthesis, the OMP-AuNPs and PE-AuNPs are subjected to characterization of their structure, morphology, and chemical properties based on UV-visible spectroscopy, FE-SEM, EDX, XRD, FT-IR, and TG/DTG analysis.

$\mathrm{UV}$-visible spectroscopy is a preliminary step in the confirmation of the synthesis and stability of AuNPs with dark purple coloration in aqueous reaction medium. The UV-visible spectra of both OMP-AuNPs and PE-AuNPs were recorded with an interval of 3 hours for 24 hours from $400 \mathrm{~nm}$ to $700 \mathrm{~nm}$, and the results are presented in Figure 2A and B. The PE-AuNPs displayed sharp peaks with the SPR absorbance maxima at $540 \mathrm{~nm}$ (Figure 2B), whereas the OMP-AuNPs displayed a small flat peak with the SPR absorbance maxima at $545 \mathrm{~nm}$ (Figure 2A). Both sets of spectral data confirmed the synthesis of AuNPs, which were concordant with the results of earlier studies. ${ }^{48}$ In general, AuNPs have been reported to exhibit a dark purple color in aqueous medium due to the intensity and size of the NPs owing to its SPR. ${ }^{48,49}$ The SPR absorbance is exceptionally sensitive to the nature, size, and shapes of the NPs formed, dielectric constant of the medium and temperature, and their interparticle distances. ${ }^{50-52}$

The surface morphology of the synthesized AuNPs was characterized by FE-SEM after 1 month of synthesis following completion of all reactions. Both the OMP-AuNPs and PE-AuNPs displayed slightly agglomerated distinct spherical structures within the nanoscale range that confirmed the synthesis of NPs (Figure 3A and B). Similar observations were reported in an earlier study. ${ }^{28,53}$ The elemental composition of the synthesized NP was confirmed by EDX analysis (Figure 4A-F). The results showed that OMPAuNPs and PE-AuNPs contained $73.87 \%$ and $64.50 \%$ gold composition, respectively (Figure 4B and E). In addition, the OMP-AuNPs contained carbon (14.46\%), oxygen (8.36\%), chlorine $(1.78 \%)$, and potassium ( $1.53 \%$; Figure $4 \mathrm{~B}$ and $\mathrm{C})$, while the PE-AuNPs contained carbon (23.48\%) and oxygen (12.02\%; Figure 4E and F), possibly due to the presence of different types of secondary metabolites such as flavonoids and phenolic compounds in OMP and peach extracts. These secondary metabolites might have acted as the reducing and stabilizing agents during the synthesis of AuNPs. ${ }^{53,54}$

The synthesized AuNPs were further characterized for their structural information and crystallinity nature by XRD analysis (Figure 5A and B). Both OMP-AuNPs and PE-AuNPs displayed five distinct diffraction peaks in the $2 \theta$ range of $10^{\circ}-90^{\circ}$ that indexed the planes (111), (200), (220), (311), and (222) of the face-centered cubic (fcc) gold particles (Figure 5A and B). These peaks were located at $37.96^{\circ}, 44.18^{\circ}, 64.51^{\circ}, 77.48^{\circ}$, and $81.74^{\circ}$, for OMP-AuNPs (Figure 5A) and $38.35^{\circ}, 44.52^{\circ}, 64.82^{\circ}$, $77.80^{\circ}$, and $82.00^{\circ}$ for PE-AuNPs (Figure 5B). The XRD analysis showed predominant peaks at (111) and (200), indicating the presence of crystallite particles displaying fcc
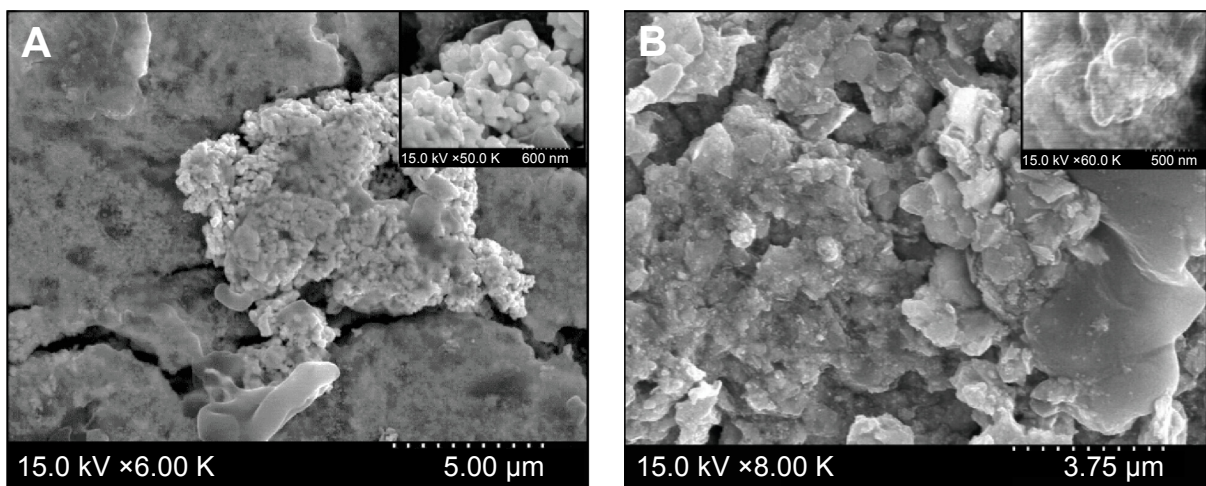

Figure 3 SEM image of synthesized OMP-AuNPs and PE-AuNPs.

Notes: (A) OMP-AuNPs; (B) PE-AuNPs.

Abbreviations: AuNPs, gold nanoparticles; OMP, oriental melon peel; PE, peach extract; SEM, scanning electron microscopy. 
A

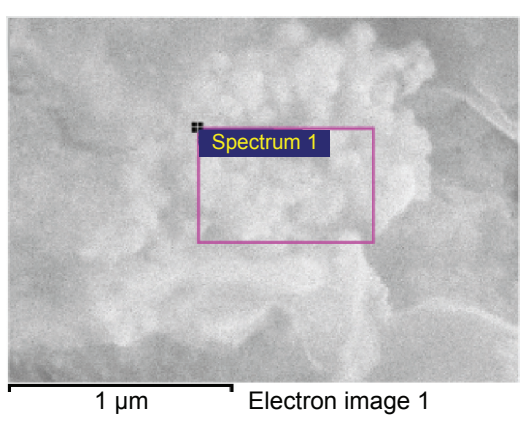

C

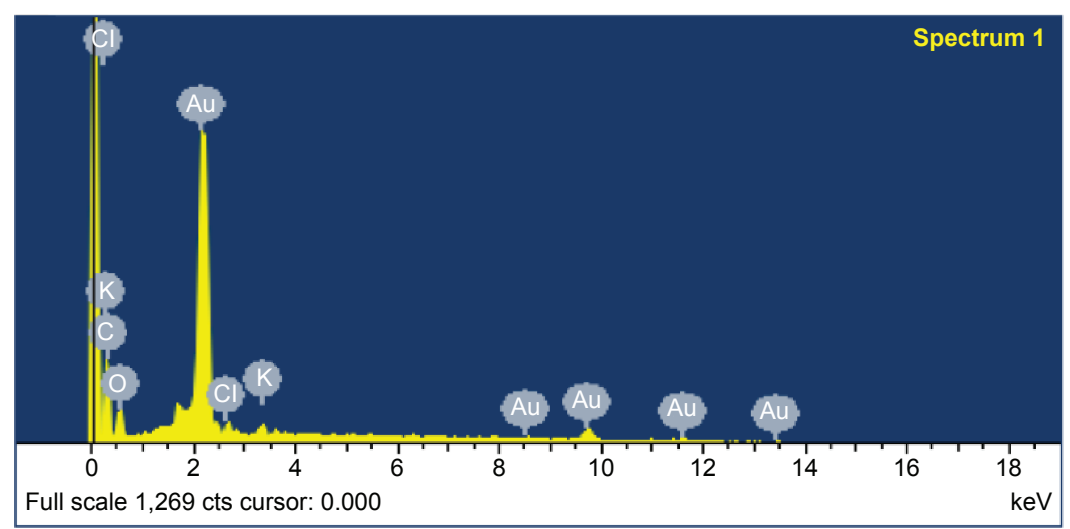

D

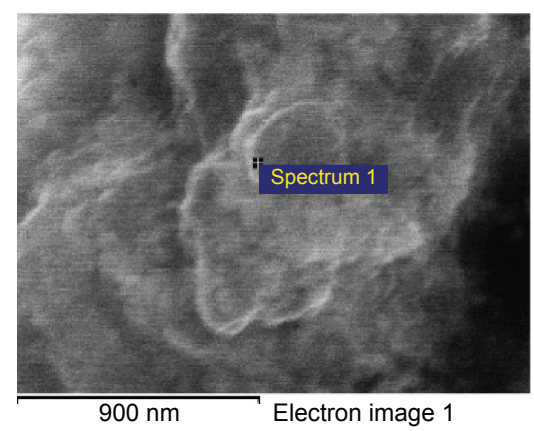

B

\begin{tabular}{|l|l|l|}
\hline Element & Weight (\%) & Atomic (\%) \\
\hline $\mathrm{C}$ & 14.46 & 54.96 \\
\hline $\mathrm{O}$ & 8.36 & 23.84 \\
\hline $\mathrm{Cl}$ & 1.78 & 2.30 \\
\hline $\mathrm{K}$ & 1.53 & 1.78 \\
\hline $\mathrm{Au}$ & 73.87 & 17.12 \\
\hline & & \\
\hline Total & 100.00 & \\
\hline
\end{tabular}

Spectrum 1

E

\begin{tabular}{|l|l|l|}
\hline Element & Weight (\%) & Atomic (\%) \\
\hline $\mathrm{C}$ & 23.48 & 64.45 \\
\hline $\mathrm{O}$ & 12.02 & 24.76 \\
\hline $\mathrm{Al}$ & 0.00 & 0.00 \\
\hline $\mathrm{P}$ & 0.00 & 0.00 \\
\hline $\mathrm{S}$ & 0.00 & 0.00 \\
\hline $\mathrm{Fe}$ & 0.00 & 0.00 \\
\hline $\mathrm{Au}$ & 64.50 & 10.79 \\
\hline & & \\
\hline Total & 100.00 & \\
\hline
\end{tabular}

$\mathbf{F}$

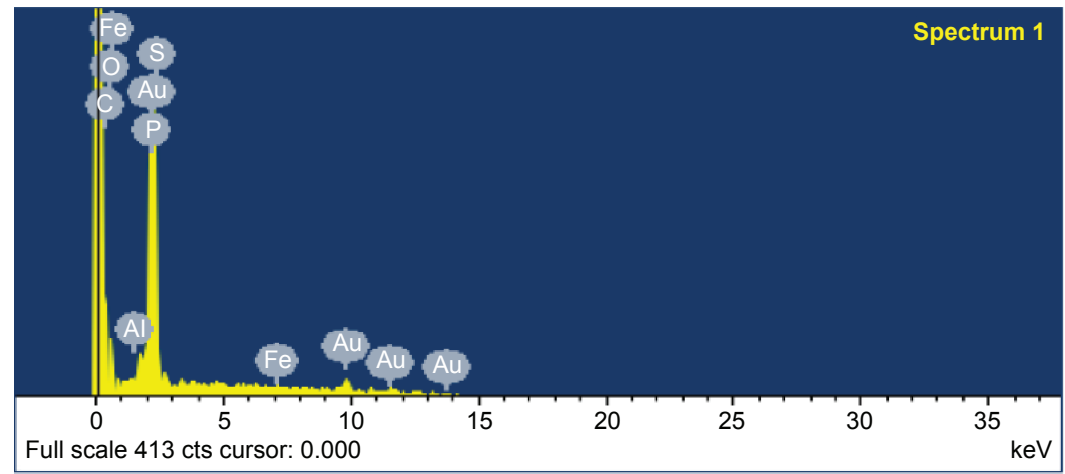

Figure 4 EDX analysis of synthesized OMP-AuNPs and PE-AuNPs.

Notes: OMP-AuNPs (A-C) and PE-AuNPs (D-F).

Abbreviations: AuNPs, gold nanoparticles; EDX, energy dispersive X-ray; OMP, oriental melon peel; PE, peach extract.

lattice structures. The fcc structures of gold matched those in the database of the Joint Committee on Powder Diffraction Standards, USA (JCPDS No 00-004-0784), confirming that the synthesized AuNPs were composed of pure crystallite gold particles. The estimated absolute crystallite size of the synthesized AuNPs was calculated to be $78.11 \mathrm{~nm}$ for OMP-AuNPs and $39.90 \mathrm{~nm}$ for PE-AuNPs based on the Scherer equation..$^{55}$ The XRD patterns of both OMP-AuNPs 

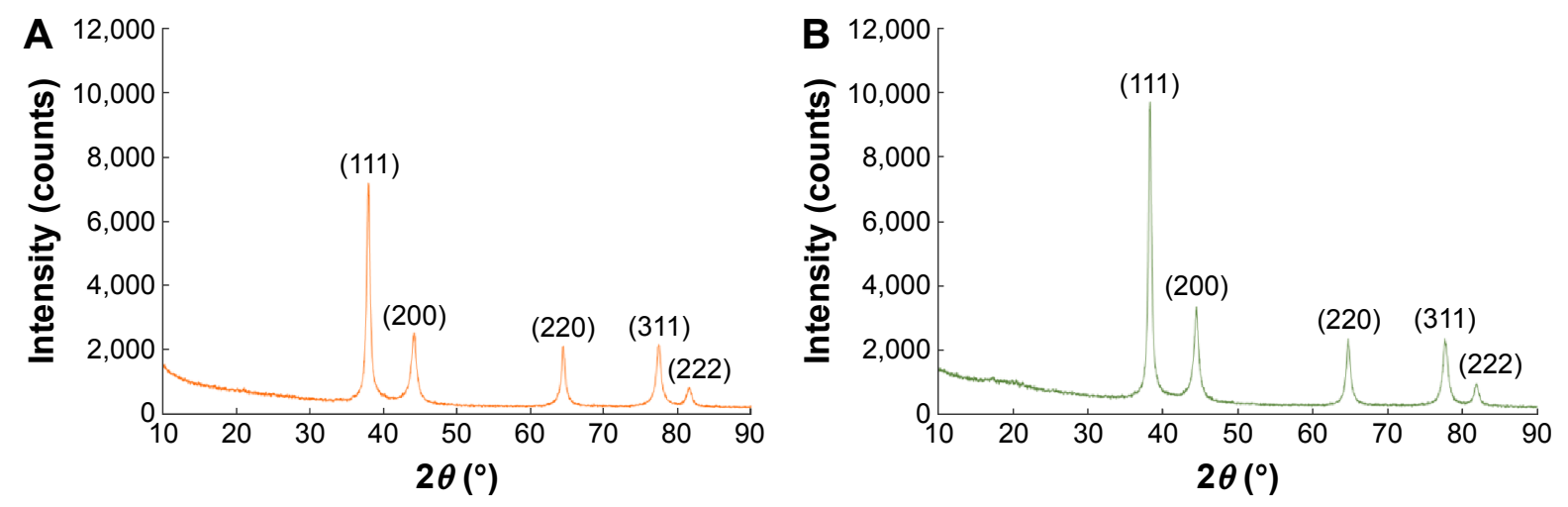

Figure 5 XRD spectra of synthesized OMP-AuNPs and PE-AuNPs.

Notes: (A) OMP-AuNPs; (B) PE-AuNPs.

Abbreviations: AuNPs, gold nanoparticles; OMP, oriental melon peel; PE, peach extract; XRD, X-ray powder diffraction.

and PE-AuNPs were consistent with the results of earlier studies of AuNPs. ${ }^{56-58}$

FT-IR analysis was conducted to identify possible functional groups responsible for the reduction of $\mathrm{AuCl}_{3}$ to AuNPs and their stabilization. FT-IR analysis of OMP, PE, OMP-AuNPs, and PE-AuNPs was performed in the range of 400-4,000 $\mathrm{cm}^{-1}$. FT-IR signals of OMP extract were observed at $3,414 \mathrm{~cm}^{-1}, 2,350 \mathrm{~cm}^{-1}, 2,156 \mathrm{~cm}^{-1}, 1,645 \mathrm{~cm}^{-1}$, $1,039 \mathrm{~cm}^{-1}, 761 \mathrm{~cm}^{-1}$, and $564 \mathrm{~cm}^{-1}$, while the FT-IR signals of OMP-AuNPs were observed at $3,410 \mathrm{~cm}^{-1}, 2,372 \mathrm{~cm}^{-1}$, $1,654 \mathrm{~cm}^{-1}, 1,018 \mathrm{~cm}^{-1}$, and $671 \mathrm{~cm}^{-1}$ (Figure 6A). Similarly, the FT-IR signals of PE were observed at $3,642 \mathrm{~cm}^{-1}$, $3,286 \mathrm{~cm}^{-1}, 2,390 \mathrm{~cm}^{-1}, 2,305 \mathrm{~cm}^{-1}, 2,147 \mathrm{~cm}^{-1}, 1,643 \mathrm{~cm}^{-1}$, $1,334 \mathrm{~cm}^{-1}, 1,018 \mathrm{~cm}^{-1}, 760 \mathrm{~cm}^{-1}$, and $652 \mathrm{~cm}^{-1}$, while the FT-IR signals of PE-AuNPs were observed at $3,547 \mathrm{~cm}^{-1}$, $2,933 \mathrm{~cm}^{-1}, 2,364 \mathrm{~cm}^{-1}, 1,654 \mathrm{~cm}^{-1}, 1,438 \mathrm{~cm}^{-1}, 1,051 \mathrm{~cm}^{-1}$, $773 \mathrm{~cm}^{-1}$, and $520 \mathrm{~cm}^{-1}$ (Figure 6B). In the case of the OMP extract, the strong peak band at $3,414 \mathrm{~cm}^{-1}$ corresponded to the $\mathrm{O}-\mathrm{H}$ stretch vibration of alcohols and phenols that was shifted toward $3,410 \mathrm{~cm}^{-1}$ in the case of OMP-AuNPs. ${ }^{59}$
Similarly, the strong peak band at $3,642 \mathrm{~cm}^{-1}$ in the peach extract corresponded to the $\mathrm{O}-\mathrm{H}$ stretch vibration and free hydroxyl groups of the alcohols and phenols that was shifted toward 3,547 $\mathrm{cm}^{-1}$ in the case of the PE-AuNPs. ${ }^{60,61}$ The bands at $1,645 \mathrm{~cm}^{-1}$ and $1,643 \mathrm{~cm}^{-1}$ in OMP and peach extracts, respectively, were due to $-\mathrm{C}=\mathrm{C}-$ stretching of carbonyl amide I vibrations that were shifted toward $1,654 \mathrm{~cm}^{-1}$ in both OMP-AuNPs and PE-AuNPs. The presence of this particular band in the AuNPs might have been due to the proteins/ peptides or amino acid groups of OMP and peach extracts, which may have acted as the reducing and capping agent for the synthesis of NPs. ${ }^{32,62}$ The peak bands at $1,039 \mathrm{~cm}^{-1}$ and $1,018 \mathrm{~cm}^{-1}$ in both OMP and peach extracts corresponded to the $\mathrm{C}-\mathrm{N}$ stretching of aliphatic amine groups and were shifted toward $1,018 \mathrm{~cm}^{-1}$ and $1,051 \mathrm{~cm}^{-1}$ in OMP-AuNPs and PE-AuNPs, respectively. ${ }^{31}$ The peak bands at $651 \mathrm{~cm}^{-1}$ and $652 \mathrm{~cm}^{-1}$ in both OMP and peach extracts corresponded to the $\mathrm{C}-\mathrm{Br}$ stretching of alkyl halide groups and were shifted toward $671 \mathrm{~cm}^{-1}$ and $520 \mathrm{~cm}^{-1}$ in OMP-AuNPs and PEAuNPs, respectively. ${ }^{63,64}$ It is speculated that the components
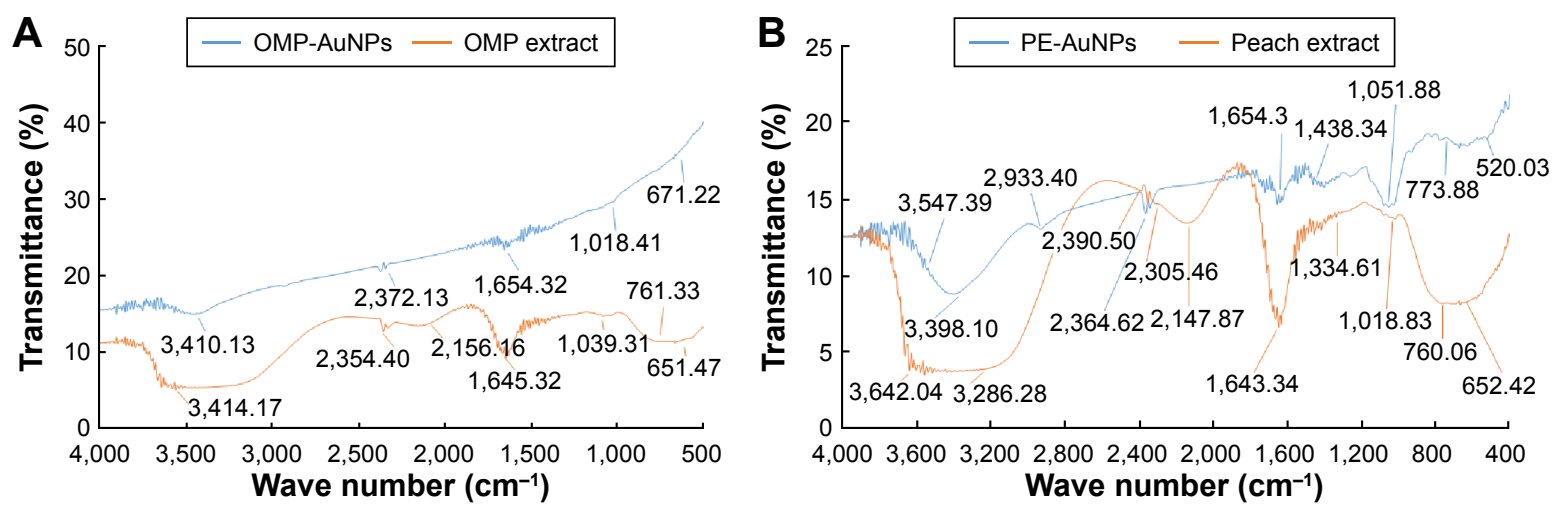

Figure 6 FT-IR analysis of synthesized OMP-AuNPs and PE-AuNPs.

Notes: (A) OMP-AuNPs; (B) PE-AuNPs.

Abbreviations: AuNPs, gold nanoparticles; FT-IR, Fourier transform infrared spectroscopy; OMP, oriental melon peel; PE, peach extract. 
of OMP and peach extracts containing $\mathrm{O}-\mathrm{H},-\mathrm{C}=\mathrm{C}-, \mathrm{C}-\mathrm{N}$, or $\mathrm{C}-\mathrm{Br}$ functional groups might have been responsible for the reduction of $\mathrm{Au}^{+}$to $\mathrm{Au}^{0}$.

The TG/DTG analysis of both the OMP-AuNPs and PEAuNPs at $20^{\circ} \mathrm{C}-700^{\circ} \mathrm{C}$ is presented in Figure $7 \mathrm{~A}$ and $\mathrm{B}$. The TG/DTG analysis of OMP-AuNPs exhibited a total weight loss of $32.75 \%$ in three phases, $20^{\circ} \mathrm{C}-210^{\circ} \mathrm{C}$ with $9.96 \%$ weight loss that is mainly due to the water molecules attached to the particles, then $210^{\circ} \mathrm{C}-440^{\circ} \mathrm{C}$ with $19.62 \%$ weight loss that corresponds to the loss of organic materials, and a third phase of weight loss of $3.17 \%$ from $440^{\circ} \mathrm{C}$ to $690^{\circ} \mathrm{C}$ due to residual compounds. Similarly, TG/DTG analysis of PE-AuNPs exhibited a total weight loss of $40.74 \%$ in three phases, $20^{\circ} \mathrm{C}-200^{\circ} \mathrm{C}, 200^{\circ} \mathrm{C}-420^{\circ} \mathrm{C}$, and $420^{\circ} \mathrm{C}-690^{\circ} \mathrm{C}$, during which there were losses of $12.32 \%, 24.88 \%$, and $3.54 \%$, respectively. The reduction in weight of the synthesized AuNPs confirmed the involvement of bioactive organic compounds from OMP and peach extracts in the reduction and stabilization of NPs. ${ }^{31,62}$

After characterization of both synthesized OMP-AuNPs and PE-AuNPs, comparative investigations of their biological potential in terms of their antibacterial, anticandidal, antioxidant, and proteasome inhibitory activities were conducted.

\section{Antibacterial activity}

Neither the OMP-AuNPs nor PE-AuNPs, nor the OMP and peach extracts (taken as extract control), exerted any antibacterial activity against the five tested foodborne pathogenic bacteria at $25 \mu \mathrm{g} /$ disk (Table 1). Similarly, the positive controls, kanamycin and rifampicin, at $5 \mu \mathrm{g} /$ disk and negative control, DMSO, did not exhibit any effects on the five tested foodborne pathogenic bacteria (Table 1). When the NPs and antibiotics were combined and the mixtures were tested for antibacterial effects, they exhibited positive synergistic responses against all the tested foodborne pathogenic bacteria (Table 1). Among the two mixtures of NPs and kanamycin, PE-AuNPs + kanamycin displayed higher synergistic activity against the four foodborne pathogenic bacteria than OMP-AuNPs + kanamycin. When the antibacterial activity of mixtures of NPs and rifampicin were compared, both exerted antibacterial activity against only three pathogenic bacteria, B. cereus ATCC 13061, E. coli ATCC 43890, and $S$. aureus ATCC 49444. Of the two mixtures of NPs/ antibiotics, PE-AuNPs with kanamycin displayed stronger synergistic antibacterial activity than OMP-AuNPs. All the mixtures of NPs/antibiotics displayed strong antibacterial synergistic activity against $S$. aureus, with inhibition zones of 13.26-25.23 mm (Table 1).

The antibacterial activities of different types of NPs have been widely investigated using different pathogenic bacteria in recent years. ${ }^{65-67}$ Earlier reports have suggested an increase in the antibacterial activity of AuNPs in response to the addition of antibiotics, ${ }^{68,69}$ which was also evident in the present investigation. It has been reported that NPs could easily penetrate the bacterial cell membrane due to their small size, causing numerous holes in the bacterial cell wall and leakage of essential elements from the cell. When applied in combination with antibiotics, NPs could influence the bacterial nucleus and DNA, causing cell death. ${ }^{66,67}$ The antimicrobial potentials of different parts of Cucumis melo
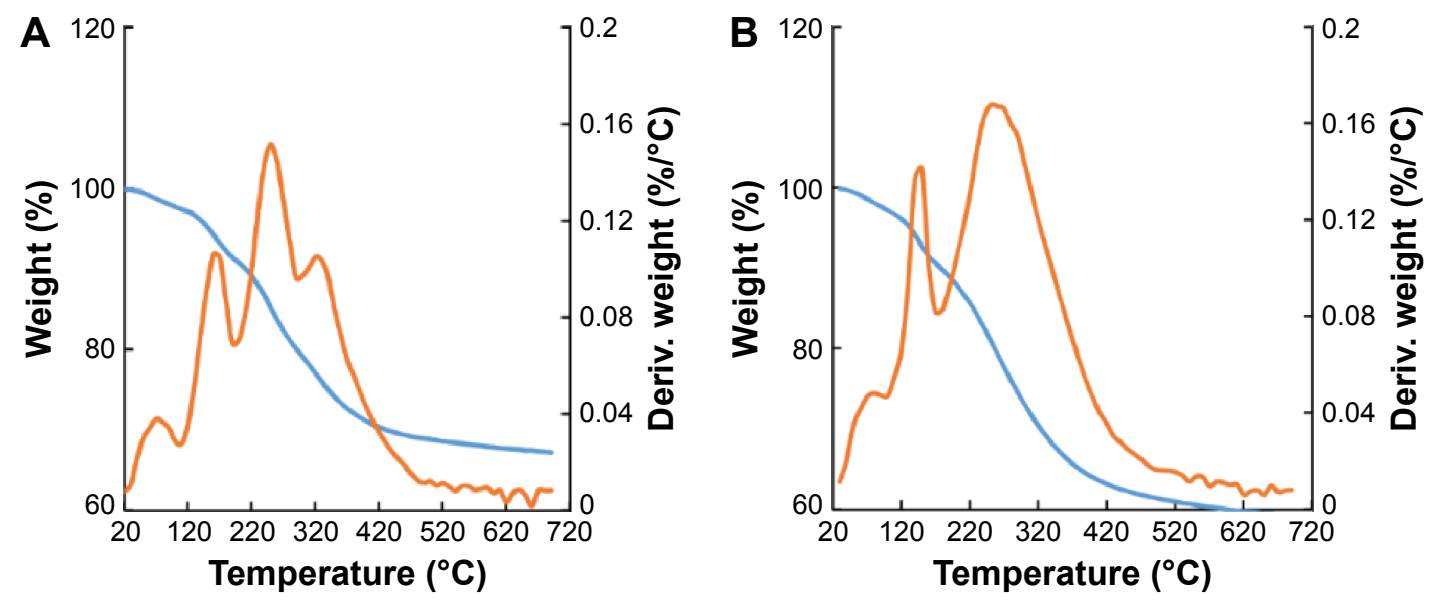

Weight $(\%) \quad$ Deriv. weight $\left(\% /{ }^{\circ} \mathrm{C}\right)$

Figure 7 TG/DTG analysis of synthesized OMP-AuNPs and PE-AuNPs.

Notes: (A) OMP-AuNPs; (B) PE-AuNPs.

Abbreviations: AuNPs, gold nanoparticles; Deriv., derivative; DTG, derivative thermogravimetric; OMP, oriental melon peel; PE, peach extract; TG, thermogravimetric. 
and Prunus persica have been reported..$^{19,70-75}$ The bioactive compounds present in peel extracts, which have been used for AuNPs synthesis and stabilization, might be responsible for the antibacterial activity of the AuNPs. The synergistic potential of AuNPs with antibiotics could be useful in minimizing the uncontrolled use of antibiotics, which would have resulted in the development of many antibiotic resistant strains.

\section{Anticandidal activity}

The synergistic anticandidal activities of both OMP-AuNPs and PE-AuNPs mixed with amphotericin B were evaluated against five different Candida species (Table 2). Initial testing of both OMP-AuNPs and PE-AuNPs at $50 \mu \mathrm{g} /$ disk and amphotericin B at $5 \mu \mathrm{g} /$ disk for their anticandidal activities revealed no inhibitory activity against any of the tested pathogenic Candida species (Table 2). However, these compounds were subsequently mixed together at the same concentrations, after which their synergistic anticandidal potentials were tested (Table 2). The extract control, positive control, and negative control did not display any inhibition activity against any of the pathogenic Candida species (Table 2). Both the OMP-AuNPs and PE-AuNPs combined with amphotericin B displayed a strong anticandidal activity against all the five tested Candida species. The AuNPs were more active against $C$. albicans KACC 30062 and C. geochares KACC 30061, as indicated by a $13.27-15.47 \mathrm{~mm}$ inhibition zone (Table 2). Among the two AuNPs, the PE-AuNPs + amphotericin B mixture exhibited a stronger positive activity than the OMP-AuNPs + amphotericin B. The comparative high anticandidal activity of PE-AuNPs could be correlated with their smaller particle size (average size $=39.90 \mathrm{~nm}$ ), which could have facilitated the easy penetration of the amphotericin B/PE-AuNPs into Candida cells, resulting in cellular lysis. The use of less amphotericin $B$ and AuNPs using the mixtures could be beneficial to clinical applications of the mixture solution, avoiding the adverse effects caused by the use of high doses of drugs. ${ }^{76}$

\section{Antioxidant activity}

The potential application of both OMP-AuNPs and PEAuNPs was evaluated in terms of its antioxidant activity by a number of in vitro antioxidant assays. The DPPH free radical scavenging potential of both OMP-AuNPs and PE-AuNPs are presented in Figure 8A. Among the two AuNPs, PE-AuNPs exhibited the stronger DPPH radical scavenging activity of $56.92 \%$ at $100 \mu \mathrm{g} / \mathrm{mL}$, while OMPAuNPs and BHT (the reference standard compound) showed activities of $26.21 \%$ and $34.82 \%$, respectively (Figure 8A). The DPPH scavenging activity of AuNPs 
Table 2 Comparative synergistic anticandidal activities of OMP-AuNPs $(50 \mu \mathrm{g})$ and PE-AuNPs $(50 \mu \mathrm{g})$ mixed with amphotericin B $(5 \mu \mathrm{g})$, a standard antifungal agent against pathogenic Candida species

\begin{tabular}{|c|c|c|c|c|c|c|c|c|}
\hline \multirow[t]{2}{*}{ Candida species } & \multicolumn{6}{|c|}{ Anticandidal activity (control samples) } & \multicolumn{2}{|c|}{ Synergistic anticandidal activity } \\
\hline & $\begin{array}{l}\text { OMP } \\
\text { extract }\end{array}$ & PE & Amphotericin B & DMSO & OMP-AuNPs & PE-AuNPs & $\begin{array}{l}\text { OMP-AuNPs + } \\
\text { amphotericin B }\end{array}$ & $\begin{array}{l}\text { PE-AuNPs + } \\
\text { amphotericin B }\end{array}$ \\
\hline Candida albicans KACC 30003 & 0 & 0 & 0 & 0 & 0 & 0 & $10.96 \pm 0.93^{e, *}$ & $10.97 \pm\left. 0.4\right|^{\mathrm{d}, \mathrm{e}}$ \\
\hline Candida albicans KACC 30062 & 0 & 0 & 0 & 0 & 0 & 0 & $14.45 \pm 0.53^{b}$ & $15.47 \pm 0.27^{\mathrm{a}}$ \\
\hline Candida glabrata KBNO6P00368 & 0 & 0 & 0 & 0 & 0 & 0 & $10.66 \pm 0.47^{\mathrm{d}, \mathrm{e}}$ & $11.09 \pm 0.66^{\mathrm{d}}$ \\
\hline Candida geochares KACC 3006I & 0 & 0 & 0 & 0 & 0 & 0 & $13.27 \pm 0.28^{c}$ & $14.25 \pm 0.22^{b}$ \\
\hline Candida saitoana KACC 4I238 & 0 & 0 & 0 & 0 & 0 & 0 & $10.09 \pm 0.30^{e}$ & $\mid \mathrm{I} .08 \pm 0.28^{\mathrm{d}, \mathrm{e}}$ \\
\hline
\end{tabular}

Notes: *Data are expressed as the mean zone of inhibition in millimeter $\pm S D$. Values with different superscript letters are significantly different at $P<0.05$.

Abbreviations: AuNPs, gold nanoparticles; DMSO, dimethyl sulphoxide; OMP, oriental melon peel; PE, peach extract; SD, standard deviation.

might be attributed to the presence of a number of secondary metabolites, mostly phenolic compounds, in the fruit peel extracts that were used for the biosynthesis of AuNPs. The potential effects of AuNPs might occur via its inhibitory effects on the peroxy radicals, which are responsible for lipid peroxidation. ${ }^{77}$

The nitric oxide scavenging potentials of AuNPs are presented in Figure 8B. Both OMP-AuNPs and PE-AuNPs displayed nitric oxide scavenging activity of $38.57 \%$ and $48.46 \%$, respectively, at $100 \mu \mathrm{g} / \mathrm{mL}$; however, the potentials were less than that of BHT, the standard reference compound, which showed $61.47 \%$ scavenging activity (Figure $8 \mathrm{~B}$ ). Nitric oxide is a very unstable compound responsible for various diseases, including cancer and inflammatory diseases; ${ }^{78,79}$
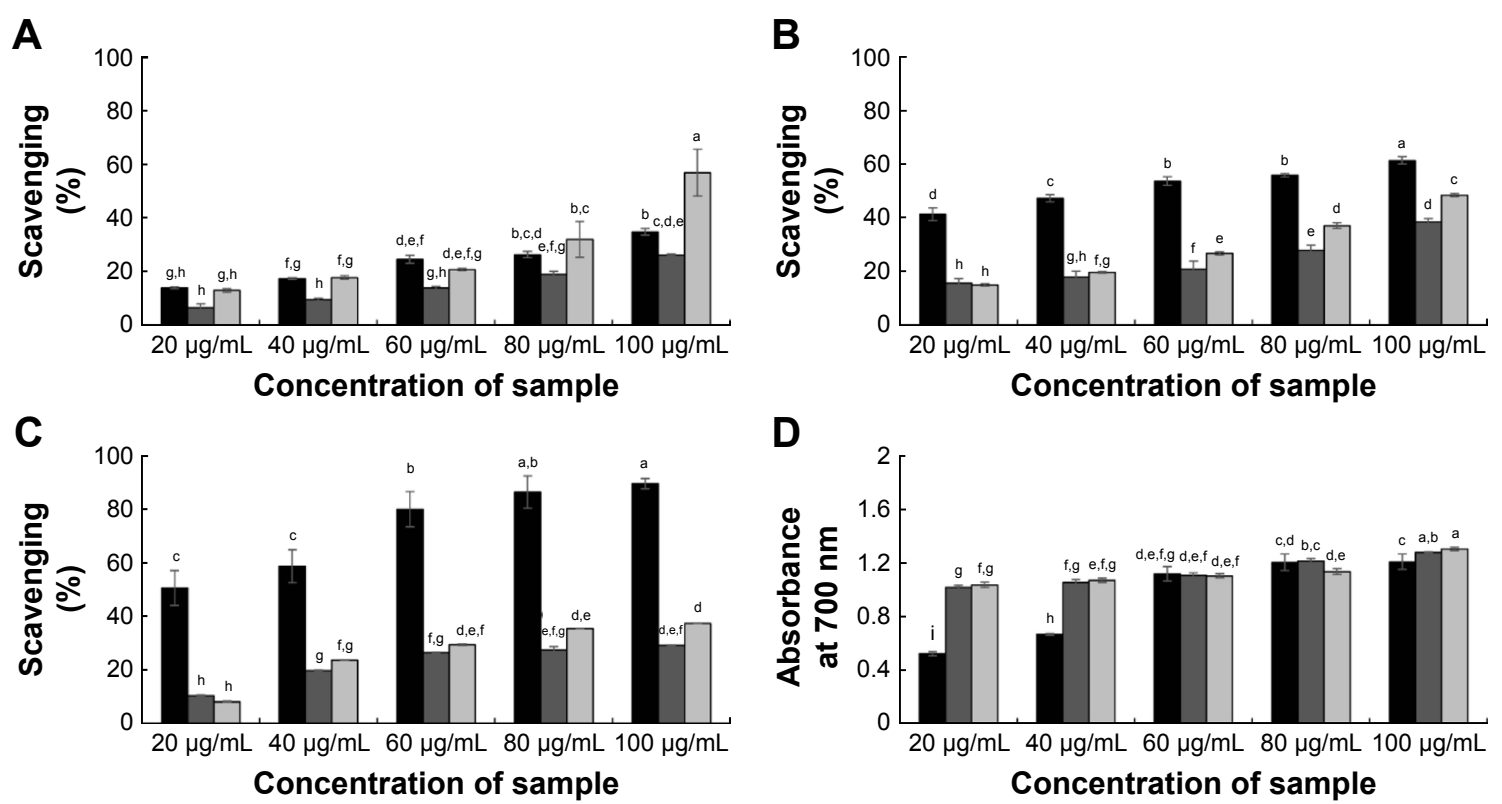

thus, the strong nitric oxide scavenging potentials of both PE-AuNPs and OMP-AuNPs could be beneficial for the biomedical and cosmetic industries.

PE-AuNPs and OMP-AuNPs also displayed moderate ABTS radical scavenging activities of $29.11 \%$ and $37.36 \%$, respectively, while that of the standard reference compound BHT was 89.61\% (Figure 8C). Moreover, they exhibited a strong reducing power of 1.28 and 1.31 absorbance at $700 \mathrm{~nm}$, while the absorbance of BHT was 1.20 (Figure 8D). The strong reducing power of both OMP-AuNPs and PEAuNPs might be attributed to the presence of phenolic compounds in the outer peel extracts. Among the AuNPs, PE-AuNPs exhibited the highest antioxidant potentials as indicated by all of the in vitro assays when compared to

MMP-AuNPs $\square$ PE-AuNPs

Figure 8 Antioxidant potential of synthesized OMP-AuNPs and PE-AuNPs.

Notes: (A) DPPH free radical scavenging potential; (B) nitric oxide scavenging potential; (C) ABTS radical scavenging potential; and (D) reducing power potential. Values with different superscript letters are significantly different at $P<0.05$.

Abbreviations: ABTS, 2,2'-azino-bis(3-ethylbenzothiazoline-6-sulphonic acid); AuNPs, gold nanoparticles; BHT, butylated hydroxyl toluene; DPPH, I,I-diphenyl-2picrylhydraxyl; OMP, oriental melon peel; PE, peach extract. 
the OMP-AuNPs. The high antioxidant potentials might be attributed to the presence of a number of phenolic compounds in the outer peel of Prunus persica, which was used for the green synthesis of PE-AuNPs. ${ }^{29}$

\section{Proteasome inhibitory activity}

The proteasome inhibitory potential of both OMP-AuNPs and PE-AuNPs is presented in Figure 9. The results showed that the values of the fluorescence unit decreased in all three PE-AuNPs, OMP-AuNPs and epoxomicin as the concentration increased, confirming their proteasome inhibitory potential (Figure 9). PE-AuNPs displayed proteasome inhibitory activities of $33.77 \%, 36.04 \%$, and $60.46 \%$ at $1 \mu \mathrm{g} / \mathrm{mL}, 10 \mu \mathrm{g} / \mathrm{mL}$, and $100 \mu \mathrm{g} / \mathrm{mL}$, respectively, while the OMP-AuNPs displayed activities of $31.74 \%, 47.67 \%$, and $55.35 \%$ at $1 \mu \mathrm{g} / \mathrm{mL}, 10 \mu \mathrm{g} / \mathrm{mL}$, and $100 \mu \mathrm{g} / \mathrm{mL}$, respectively. Epoxomicin, the reference standard, displayed $30.28 \%, 40.06 \%$, and $45.67 \%$ activity at concentrations of $0.56 \mu \mathrm{g} / \mathrm{mL}, 2.78 \mu \mathrm{g} / \mathrm{mL}$, and $5.56 \mu \mathrm{g} / \mathrm{mL}$, respectively. The results confirmed that PE-AuNPs displayed a stronger proteasome inhibitory activity than OMP-AuNPs and epoxomicin, which might have been due to the presence of a number of compounds, including chlorogenic acid, catechin, epicatechin, rutin, and cyanidin-3-glucoside in the outer peel of Prunus persica that was used for the biosynthesis of PE-AuNPs. It is well known that cancer cells have defective cell cycle checkpoints and DNA repair control mechanisms, while proteasomes are responsible

$\begin{array}{lll}\rightarrow \text { Control } & \leftarrow \text { OMP-AuNP_1 } & \leftarrow \text { OMP-AuNP_10 } \\ \leftarrow \text { OMP-AuNP_100 } & - \text { Epox_1 } & \rightarrow \text { Epox_5 } \\ \leftarrow \text { Epox_10 } & \rightarrow \text { PE-AuNP_1 } & - \text { PE-AuNP_10 } \\ \rightarrow \text { PE-AuNP_100 } & \end{array}$

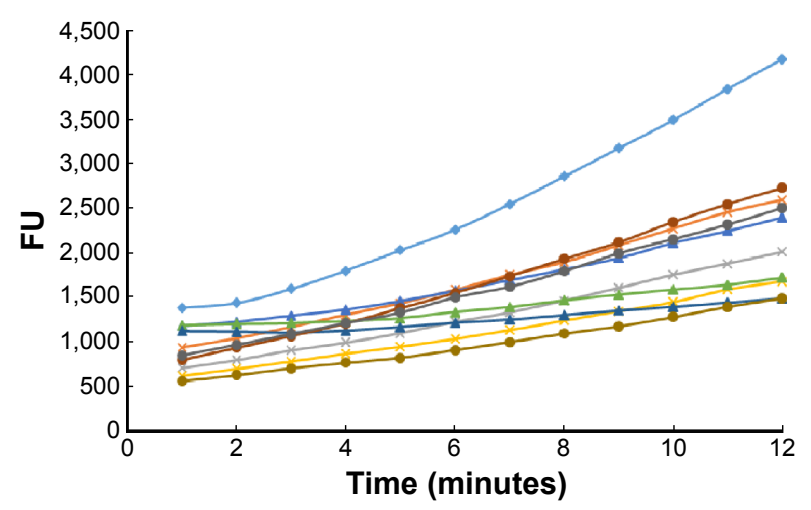

Figure 9 Proteasome inhibitory potential of both OMP-AuNPs and PE-AuNPs and standard reference compound, Epox.

Notes: $100 \mu \mathrm{g} / \mathrm{mL}$ (OMP-AuNP_100, PE-AuNP_100); $10 \mu \mathrm{g} / \mathrm{mL}$ (OMP-AuNP_10, PE-AuNP_I0); I $\mu \mathrm{g} / \mathrm{mL}$ (OMP-AuNP_I, PE-AuNP_I) and $5.56 \mu \mathrm{g} / \mathrm{mL}$ (Epox_10); $2.78 \mu \mathrm{g} / \mathrm{mL}$ (Epox_5) and $0.56 \mu \mathrm{g} / \mathrm{mL}$ (Epox_l).

Abbreviations: AuNPs, gold nanoparticles; FU, fluorescence units; Epox, epoxomicin; OMP, oriental melon peel; $\mathrm{PE}$, peach extract. for the degradation of many cytosolic proteins, including cyclins, misfolded, or denatured proteins, and transcription factors in cells. ${ }^{80,81}$ If these cancer cells are placed under stress conditions by the use of proteasome inhibitors such as AuNPs, they will then face tremendous problems and not be able to correct the cell cycle transition blockade. As a result, they may enter the apoptosis phase without affecting the normal cell. ${ }^{82}$ Both PE-AuNPs and OMPAuNPs with potent proteasome inhibitory potential could serve as potential candidates for targeted drug delivery and drug conjugation with efficient anticancer drugs in cancer treatment.

\section{Conclusion}

In the current study, the biosynthesis of AuNPs was attempted using the outer peel extracts of Cucumis melo and Prunus persica fruits as the sole reducing agents. To the best of our knowledge, the use of naturally available fruit waste materials has not been investigated for such applications to date. The NPs were synthesized utilizing green technology, which is a nontoxic and environmental friendly procedure and is better than the conventional physical and chemical methods that give rise to highly toxic products. The synthesized NPs were subjected to a number of characterization techniques, including UV-visible spectroscopy, FE-SEM, EDX, XRD, FT-IR, and TG/DTG analysis, and confirmed to be AuNPs. The estimated absolute crystallite size of the synthesized AuNPs was calculated to be $78.11 \mathrm{~nm}$ for OMP-AuNPs and $39.90 \mathrm{~nm}$ for PE-AuNPs based on the Scherer equation. Both synthesized AuNPs were evaluated for antibacterial, anticandidal, antioxidant, and proteasome inhibitory potential. Among the synthesized NPs, the PE-AuNPs were found to be the most promising NPs, with strong antibacterial, anticandidal, antioxidant, and proteasome inhibitory activities. Bioactive compounds such as chlorogenic acid, catechin, epicatechin, rutin, and cyanidin-3-glucoside, which are the major constituents of peach fruits as evident from previous published literatures, might be responsible for the potential activity of PE-AuNPs. The significant biological properties of both synthesized ecofriendly NPs could make them promising candidates in biomedical, pharmaceutical, food, and cosmetic industries.

\section{Acknowledgment}

This work was supported by grants from the Systems and Synthetic Agro-biotech Center through the Next-Generation Bio-Green 21 Program (PJ011117), Rural Development Administration, South Korea. 


\section{Disclosure}

The authors report no conflicts of interest in this work.

\section{References}

1. Nanda A, Saravanan M. Biosynthesis of silver nanoparticles from Staphylococcus aureus and its antimicrobial activity against MRSA and MRSE. Nanomed Nanotechnol Biol Med. 2009;5(4):452-456.

2. Daniel MC, Astruc D. Gold nanoparticles: assembly, supramolecular chemistry, quantum-size-related properties, and applications toward biology, catalysis, and nanotechnology. Chem Rev. 2004;104(1): 293-346.

3. Zhan G, Huang J, Lin L, Lin W, Emmanuel K, Li Q. Synthesis of gold nanoparticles by Cacumen Platycladi leaf extract and its simulated solution: toward the plant-mediated biosynthetic mechanism.J Nanopart Res. 2011;13(10):4957-4968.

4. Kumar A, Kaur K, Sharma S. Synthesis, characterization and antibacterial potential of silver nanoparticles by Morus nigra leaf extract. Indian J Pharma Biol Res. 2013;1(4):16-24.

5. Xia Y, Xiong Y, Lim B, Skrabalak SE. Shape-controlled synthesis of metal nanocrystals: simple chemistry meets complex physics? Angew Chem Int Ed Engl. 2009;48(1):60-103.

6. Yu DB, Yam VW. Hydrothermal-induced assembly of colloidal silver spheres into various nanoparticles on the basis of HTAB-modified silver mirror reaction. J Phys Chem B. 2005;109(12):5497-5503.

7. Pal A, Shah S, Devi S. Preparation of silver, gold and silver-gold bimetallic nanoparticles in w/o microemulsion containing TritonX-100. Colloid Surf A. 2007;302(1-3):483-487.

8. Lu X, Yavuz MS, Tuan HY, Korgel BA, Xia Y. Ultrathin gold nanowires can be obtained by reducing polymeric strands of oleylamine$\mathrm{AuCl}$ complexes formed via aurophilic interaction. $\mathrm{J} \mathrm{Am} \mathrm{Chem} \mathrm{Soc}$ 2008;130(28):8900-8901.

9. Mohanpuria P, Rana NK, Yadav SK. Biosynthesis of nanoparticles: technological concepts and future applications. J Nanopart Res. 2008;10(3): 507-517.

10. Gericke M, Pinches A. Microbial production of gold nanoparticles. Gold Bull. 2006;39(1):22-28.

11. Shankar SS, Ahmad A, Sastry M. Geranium leaf assisted biosynthesis of silver nanoparticles. Biotechnol Prog. 2003;19(6):1627-1631.

12. Lim TK. Cucumis melo (Makuwa Group). Edible Medicinal and NonMedicinal Plants. Vol. 2. London: Springer; 2012:219.

13. Chen L, Kang YH. In vitro inhibitory effect of oriental melon (Cucumis melo L. var. makuwa Makino) seed on key enzyme linked to type 2 diabetes: assessment of anti-diabetic potential of functional food. J Funct Foods. 2013;5(2):981-986.

14. Chen L, Kang YH, Suh JK. Roasting processed oriental melon (Cucumis melo L. var. makuwa Makino) seed influenced the triglyceride profile and the inhibitory potential against key enzymes relevant for hyperglycemia. Food Res Int. 2014;56:236-242.

15. Faust M, Timon B. Origin and dissemination of peach. In: Janick J, editor. Horticultural Reviews. Vol 17. Oxford, UK: John Wiley \& Sons, Inc; 1995.

16. Yang Z, Ma Y, Chen L, et al. Differential transcript abundance and genotypic variation of four putative allergen-encoding gene families in melting peach. Tree Genet Genomes. 2011;7:903-916.

17. Manzoor M, Anwar F, Mahmood Z, Rashid U, Ashraf M. Variation in minerals, phenolics and antioxidant activity of peel and pulp of different varieties of peach (Prunus persica L.) fruit from Pakistan. Molecules. 2012;17(6):6491-6506.

18. Andreotti C, Ravaglia D, Ragaini A, Costa G. Phenolic compounds in peach (Prunus persica) cultivars at harvest and during fruit maturation. Annal Appl Biol. 2008;153:11-23.

19. Aziz S, Rahman HU. Biological activities of Prunus persica L. batch. J Med Plants Res. 2013;7:947-951.

20. Magudapathy P, Gangopadhyay P, Panigrahi BK, Nair KGM, Dhara S. Electrical transport studies of $\mathrm{Ag}$ nanoclusters embedded in glass matrix. Physica B. 2001;299:142-146.
21. Jennings T, Strouse G. Past, present, and future of gold nanoparticles. Adv Exp Med Biol. 2007;620:34-47.

22. Lee KS, El-Sayed MA. Gold and silver nanoparticles in sensing and imaging: sensitivity of plasmon response to size, shape, and metal composition. J Phys Chem B. 2006;110(39):19220-19225.

23. Salata OV. Applications of nanoparticles in biology and medicine. J Nanobiotechnol. 2004;2(1):3.

24. El-Sayed IH, Huang X, El-Sayed MA. Selective laser photo-thermal therapy of epithelial carcinoma using anti-EGFR antibody conjugated gold nanoparticles. Cancer Lett. 2006;239(1):129-135.

25. Shankar SS, Rai A, Ankamwar B, Singh A, Ahmad A, Sastry M. Biological synthesis of triangular gold nanoprisms. Nat Mater. 2004;3(7):482-488.

26. Chandran SP, Chaudhary M, Pasricha R, Ahmad A, Sastry M. Synthesis of gold nanotriangles and silver nanoparticles using Aloe vera plant extract. Biotechnol Progr. 2006;22(2):577-583.

27. MubarakAli D, Thajuddin N, Jeganathan K, Gunasekaran M. Plant extract mediated synthesis of silver and gold nanoparticles and its antibacterial activity against clinically isolated pathogens. Colloid Surface B. 2011;85(2):360-365.

28. Elia P, Zach R, Hazan S, Kolusheva S, Porat Z, Zeiri Y. Green synthesis of gold nanoparticles using plant extracts as reducing agents. Int $J$ Nanomed. 2014;9:4007-4021.

29. Bankar A, Joshi B, Kumara AR, Zinjarde S. Banana peel extract mediated synthesis of gold nanoparticles. Colloid Surface B. 2010;80(1): 45-50.

30. Patra JK, Baek KH. Novel green synthesis of gold nanoparticles using Citrullus lanatus rind and investigation of proteasome inhibitory activity, antibacterial, and antioxidant potential. Int J Nanomedicine. 2015;10: 7253-7264.

31. Basavegowda N, Idhayadhulla A, Lee YR. Phyto-synthesis of gold nanoparticles using fruit extract of Hovenia dulcis and their biological activities. Ind Crop Prod. 2014;52:745-751.

32. Prakash P, Gnanaprakasam P, Emmanuel R, Arokiyaraj S, Saravanan M. Green synthesis of silver nanoparticles from leaf extract of Mimusops elengi, Linn. for enhanced antibacterial activity against multi drug resistant clinical isolates. Colloid Surface B. 2013;108:255-259.

33. Diao WR, Hu QP, Feng SS, Li WQ, Xu JG. Chemical composition and antibacterial activity of the essential oil from green huajiao (Zanthoxylum schinifolium) against selected foodborne pathogens. J Agric Food Chem. 2013;61(25):6044-6049.

34. Naqvi SZ, Kiran U, Ali MI, et al. Combined efficacy of biologically synthesized silver nanoparticles and different antibiotics against multidrug-resistant bacteria. Int J Nanomed. 2013;8:3187-3195.

35. Murray PR, Baron EJ, Pfaller MA, Tenover FC, Yolke RH. Manual of Clinical Microbiology. 6th ed. Washington, DC: ASM Press; 1995.

36. Braca A, Tommasi ND, Bari LD, Pizza C, Politi M, Morelli I. Antioxidant principles from Bauhinia terapotensis. J Nat Prod. 2001;64(7): 892-895.

37. Makhija IK, Aswatha-Ram HN, Shreedhara CS, Vijay Kumar S, Devkar R. In vitro antioxidant studies of sitopaladi churna, a polyherbal ayurvedic formulation. Free Rad Antioxidants. 2011;1:37-41.

38. Thaipong K, Boonprakob U, Crosby K, Cisneros-Zevallos L, Byrne DH. Comparison of ABTS, DPPH, FRAP, and ORAC assays for estimating antioxidant activity from guava fruit extracts. J Food Comp Anal. 2006;19:669-675.

39. Patra JK, Kim SH, Hwang H, Choi JW, Baek KH. Volatile compounds and antioxidant capacity of the bio-oil obtained by pyrolysis of Japanese red pine (Pinus Densiflora Siebold and Zucc.). Molecules. 2015;20(3): 3986-4006.

40. Higashi-Okai K, Kamimoto K, Yoshioka A, Okai Y. Potent suppressive activity of fresh and dried peels from Satsuma mandarin (Citrus unshiu Marcorv.) on hydroperoxide generation from oxidized linoleic acid. Phytother Res. 2002;16(8):781-784.

41. Leontowicz M, Gorinstein S, Leontowicz H, et al. Apple and pear peel and pulp and their influence on plasma lipids and antioxidant potentials in rats fed cholesterol-containing diets. J Agric Food Chem. 2003;51(19): $5780-5785$. 
42. Anagnostopoulou MA, Kefalas P, Kokkalou E, Assimopoulou AN, Papageorgiou VP. Analysis of antioxidant compounds in sweet orange peel by HPLC-diode array detection-electrospray ionization mass spectrometry. Biomed Chromatogr. 2005;19(2):138-148.

43. Parmar HS, Kar A. Protective role of Mangifera indica, Cucumis melo and Citrullus vulgaris peel extracts in chemically induced hypothyroidism. Chem Biol Interact. 2009;177(3):254-258.

44. Parmar HS, Kar A. Protective role of Citrus sinensis, Musa paradisiaca, and Punica granatum against diet-induced atherosclerosis and thyroid dysfunctions in rats. Nutr Res. 2007;27:710-718.

45. Mukherjee P, Senapati S, Mandal D, et al. Extracellular synthesis of gold nanoparticles by the fungus Fusarium oxysporum. Chem Bio Chem. 2002;3(5):461-463.

46. SasiKumar R, Priyadharshini S, Nandha Kumar KPL, Nivedha S. In vitro pharmacognostical studies and evaluation of bioactive constituents from the fruits of Cucumis melo L. (Muskmelon). Int J Pharma Phytochem Res. 2014;6:936-941.

47. Mehra M, Pasricha V, Gupta RK. Estimation of nutritional, phytochemical and antioxidant activity of seeds of musk melon (Cucumis melo) and water melon (Citrullus lanatus) and nutritional analysis of their respective oils. J Pharma Phytochem. 2015;3:98-102.

48. Mulvaney P. Surface plasmon spectroscopy of nanosized metal particles. Langmuir. 1996;12:788-800.

49. Sosa ME, Eppinger SD, Rowles CM. Identifying modular and integrative systems and their impact on design team interactions. J Mech Des. 2003; $125: 240-252$

50. Link S, El-Sayed MA. Size and temperature dependence of the plasmon absorption of colloidal gold nanoparticles. J Phys Chem B. 1999; 103:4212-4217.

51. Sun Y, Xia Y. Increased sensitivity of surface plasmon resonance of gold nanoshells compared to that of gold solid colloids in response to environmental changes. Anal Chem. 2002;74(20):5297-5305.

52. Islam NU, Jalil K, Shahid M, Muhammad N, Rauf A. Pistacia integerrima gall extract mediated green synthesis of gold nanoparticles and their biological activities. Arabian J Chem. 2015:1-10.

53. Varun S, Sellappa S, RafiqKhan M, Vijayakumar S. Green synthesis of gold nanoparticles using Argemone mexicana L. leaf extract and its characterization. Int J Pharm Sci Rev Res. 2015;32:42-44.

54. Rimal Isaac RS, Sakthivel G, Murthy C. Green synthesis of gold and silver nanoparticles using Averrhoa bilimbi fruit extract. J Nanotechnol. 2013;2013:6.

55. Aftabtalab A, Sadabadi H. Application of magnetite $\left(\mathrm{Fe}_{3} \mathrm{O}_{4}\right)$ nanoparticles in hexavalent chromium adsorption from aquatic solutions. J Pet Environ Biotechnol. 2015;6:200.

56. Kannan P, John SA. Synthesis of mercaptothiadiazole functionalized gold nanoparticles and their self-assembly on Au substrates. Nanotechnol. 2008;19(8):085602.

57. Li Z, Friedrich A, Taubert A. Gold microcrystal synthesis via reduction of $\mathrm{HAuCl}_{4}$ by cellulose in the ionic liquid 1-butyl-3-methyl imidazolium chloride. J Mater Chem. 2008;18(9):1008-1014.

58. Ghodake GS, Deshpande NG, Lee YP, Jin ES. Pear fruit extract-assisted room-temperature biosynthesis of gold nanoplates. Colloid Surface B. 2010;75(2):584-589.

59. Prathna TC, Chandrasekaran N, Raichur AM, Mukherjee A. Biomimetic synthesis of silver nanoparticles by Citrus limon (lemon) aqueous extract and theoretical prediction of particle size. Colloid Surface B. 2011;82(1): $152-159$.

60. Narayanan KB, Sakthivel N. Phytosynthesis of gold nanoparticles using leaf extract of Coleus amboinicus Lour. Mater Charact. 2010;61: $1232-1238$

61. Babu PJ, Sharma P, Kalita MC, Bora U. Green synthesis of biocompatible gold nanoparticles using Fagopyrum esculentum leaf extract. Front Mater Sci. 2011;5:379-387.

62. Sau TK, Rogach AL. Nonspherical noble metal nanoparticles: colloidchemical synthesis and morphology control. Adv Mater. 2010;22(16): 1781-1804
63. Williams DH, Fleming I. Spectroscopic methods in organic chemistry. New York, NY: The McGraw-Hill; 1995.

64. Coates J. Interpretation of infrared spectra, a practical approach. In: Meyers RA, editor. Encyclopedia of Analytical Chemistry. Chichester: John Wiley \& Sons Ltd; 2000:10815-10837.

65. Yoon KY, Hoon Byeon J, Park JH, Hwang J. Susceptibility constants of Escherichia coli and Bacillus subtilis to silver and copper nanoparticles. Sci Total Environ. 2007;373(2-3):572-575.

66. Ruparelia JP, Chatterjee AK, Duttagupta SP, Mukherji S. Strain specificity in antimicrobial activity of silver and copper nanoparticles. Acta Biomater. 2008;4(3):707-716.

67. Azam A, Ahmed AS, Oves M, Khan MS, Habib SS, Memic A. Antimicrobial activity of metal oxide nanoparticles against Gram-positive and Gram-negative bacteria: a comparative study. Int J Nanomed. 2012;7: 6003-6009.

68. Burygin GL, Khlebtsov BN, Shantrokha AN, Dykman LA, Bogatyrev VA, Khlebtsov NG. On the enhanced antibacterial activity of antibiotics mixed with gold nanoparticles. Nanoscale Res Lett. 2009;4(8):794-801.

69. Ravishankar Rai V, Bai AJ. Nanoparticles and their potential application as antimicrobials. In: Mendez-Vilas A, editor. Science against microbial pathogens: communicating current research and technological advances. Badajoz, Spain: Formatex Research Center; 2011: 197-209.

70. Raturi R, Singh H, Bahuguna P, Sati SC, Badoni PP. Antibacterial and antioxidant activity of methanolic extract of bark of Prunus persica. J Appl Nat Sci. 2011;3:312-314.

71. Baranwal A, Arora S, Kumar RG, et al. Evaluation of the combinational antimicrobial effect of Prunus persia and Annona squamosa seeds methanolic extract on standard microbial strains. Global J Biosci Biotechnol. 2013;2:571-575.

72. Manzoor M, Naseer S, Jabeen R, Manzoor M. Antibacterial activity of fruits against Escherichia coli. ARPN J Agric Biol Sci. 2013;8: 258-263.

73. Siddeeg A, Alsir E, Xu Y, Jiang Q, Xia W. Chemical composition and antibacterial activity of the essential oil isolated from seinat (Cucumis melo Var. Tibish) Seeds. Int J Technol Enhancements Emerging Engineer Res. 2014;2:120-124.

74. Edrah S, Alafid F, Kumar A. Preliminary Phytochemical screening and preliminary phytochemical screening and antibacterial activity of Pistacia atlantica and Prunus persica plants of Libyan origin. Int J Sci Res. 2015;4:1552-1555.

75. Thakur HA. Antimicrobial and antifungal activity of Cucumis melo L. (cucurbitaceae) and Pergularia daemia Frosk. (asclpiadaceae) an ethnomedicinal plants. Int J Bioassay. 2015;4:3661-3665.

76. Gajbhiye M, Kesharwani J, Ingle A, Gade A, Rai M. Fungus-mediated synthesis of silver nanoparticles and their activity against pathogenic fungi in combination with fluconazole. Nanomed Nanotechnol Biol Med. 2009;5(4):382-386.

77. Cheng R, Glynn S, Santana WF, Switzer C, Ridnour L, Wink DA. Nitric oxide and redox inflammation in cancer. Adv Mol Toxicol. 2010;4: $157-182$.

78. Soneja A, Drews M, Malinski T. Role of nitric oxide, nitroxidative and oxidative stress in wound healing. Pharmacol Rep. 2005;57(Suppl): 108-119.

79. Royer M, Prado M, Garcia-Perez ME, Diouf PN, Stevanovic T. Study of nutraceutical, nutricosmetics and cosmeceutical potentials of polyphenolic bark extracts from Canadian forest species. Pharm Nutr. 2013;1: 158-167.

80. Kisselev AF. Joining the army of proteasome inhibitors. Chem Biol. 2008; $15(5): 419-421$

81. Tanaka T, Nakatani T, Kamitani T. Inhibition of NEDD8-conjugation pathway by novel molecules: potential approaches to anticancer therapy. Mol Oncol. 2012;6(3):267-275.

82. Almond JB, Cohen GM. The proteasome: a novel target for cancer chemotherapy. Leukemia. 2002;16(4):433-443. 
International Journal of Nanomedicine

Dovepress

\section{Publish your work in this journal}

The International Journal of Nanomedicine is an international, peerreviewed journal focusing on the application of nanotechnology in diagnostics, therapeutics, and drug delivery systems throughout the biomedical field. This journal is indexed on PubMed Central, MedLine, CAS, SciSearch ${ }^{\circledR}$, Current Contents ${ }^{\circledR} /$ Clinical Medicine,
Journal Citation Reports/Science Edition, EMBase, Scopus and the Elsevier Bibliographic databases. The manuscript management system is completely online and includes a very quick and fair peer-review system, which is all easy to use. Visit http://www.dovepress.com/ testimonials.php to read real quotes from published authors.

Submit your manuscript here: http://www.dovepress.com/international-journal-of-nanomedicine-journal 